\title{
Patrón nodular centrilobulillar
}

\section{Centrilobular nodular pattern}

Jorge Carrillo B., MD. (1); Claudia Patricia Zuluaga Gómez, MD. ${ }^{(1)}$; Melissa KaLLmanN S., MD. ${ }^{(2)}$

${ }^{(1)}$ Radiología - Hospital Universitario Mayor Mederi, Bogotá, Colombia.

${ }^{(2)}$ Medicina Interna - Radiología - Universidad del Rosario, Bogotá, Colombia. Correspondencia: Claudia Patricia Zuluaga Gómez, correo electrónico: patozulua@ gmail.com

Recibido: 01/08/15. Aceptado: 10/08/15.
El término de nódulo se utiliza para describir una opacidad pulmonar redondeada, bien o mal definida, menor de $3 \mathrm{~cm}$ de diámetro. El análisis de las lesiones nodulares del parénquima pulmonar debe incluir tamaño, contornos, densidad y localización. Los nódulos menores de 10 $\mathrm{mm}$ de diámetro se consideran nódulos pequeños $(1,2)$. La sociedad Fleishner define como micronódulos a los nódulos menores de $3 \mathrm{~mm}$ de diámetro. En general, el término de patrón nodular hace referencia a lesiones nodulares pequeñas, múltiples, en el parénquima pulmonar. $\mathrm{La}$ localización de los nódulos en relación con las estructuras del lobulillo pulmonar secundario, permite estrechar el diagnóstico diferencial y categoriza el patrón nodular en: perilinfático, aleatorio y centrilobulillar (1).

Los nódulos centrilobulillares pueden asociarse a enfermedad intersticial o del espacio aéreo y presentan densidades variables (sólidos o en vidrio esmerilado), contornos bien o mal definidos y tamaños entre 2 y $10 \mathrm{~mm}$. En general, se encuentran separados de la pleura y la distancia entre nódulo y nódulo es similar.

El hallazgo de un nódulo centrilobulillar sugiere alteraciones relacionadas con estructuras anatómicas del centro del lobulillo pulmonar secundario (bronquiolo y arteriola). En pacientes con patrón nodular centrilobulillar, la presencia de imágenes de "árbol en gemación" sugiere etiología infecciosa o broncoaspiración. Sin embargo, el diagnóstico diferencial de patrón nodular centrilobulillar es amplio y en ausencia de "árbol en gemación "se deben considerar en el diagnóstico diferencial entidades de naturaleza diversa que incluyen: neumonitis de hipersensibilidad, bronquiolitis respiratoria y vasculitis de vaso pequeño (1) (tabla 1).

\section{Neumonitis de hipersensibilidad}

La neumonitis de hipersensibilidad $(\mathrm{NH})$, también conocida como alveolitis alérgica extrínseca, se relaciona con síntomas respiratorios por la respuesta inmunológica a un antígeno inhalado en un paciente previamente sensibilizado. El patrón nodular centrilobulillar que se visualiza en pacientes con $\mathrm{NH}$ puede relacionarse con bronquiolitis celular, neumonitis intersticial peribronquiolar o áreas focales de neumonía de organización. Otras alteraciones evidentes en la tomografía de alta resolución pacientes con $\mathrm{NH}$ incluyen: patrón en vidrio esmerilado, consolidación, mosaico de atenuación y quistes (3, 4) (figura 1).

\section{Granulomatosis eosinofílica con poliangeitis (síndrome de Churg-Strauss)}

Esta entidad forma parte de las vasculitis de pequeño vaso ANCA (+). El patrón nodular centrilobulillar descrito en la enfermedad puede 
Tabla 1. Diagnósticos diferenciales.

\begin{tabular}{|c|c|}
\hline Bron & Vasculares \\
\hline $\begin{array}{l}\text { - Infección bacteriana } \\
\text { - Infección por } \\
\text { micobacterias } \\
\text { - Aspergilosis } \\
\text { broncopulmonar } \\
\text { alérgica } \\
\text { - Fibrosis quística } \\
\text { - Asma } \\
\text { - Panbronquiolitis } \\
\text { difusa } \\
\text { - Neumonitis de } \\
\text { hipersensibilidad } \\
\text { - Bronquiolitis } \\
\text { aspirativa } \\
\text { - Neumonía } \\
\text { intersticial linfocítica }\end{array}$ & $\begin{array}{l}\text { - Vasculitis de vaso pequeño } \\
\text { a. Poliangeitis } \\
\text { granulomatosa } \\
\text { (Wegener) } \\
\text { b. Poliangeitis microscópica } \\
\text { (PAM) } \\
\text { c. Granulomatosis } \\
\text { eosinofílica con } \\
\text { poliangeitis (Churg- } \\
\text { Strauss) } \\
\text { - Edema pulmonar } \\
\text { - Hemorragia pulmonar } \\
\text { - Microangiopatía trombótica } \\
\text { tumoral } \\
\text { - Granulomatosis por } \\
\text { celulosa }\end{array}$ \\
\hline
\end{tabular}

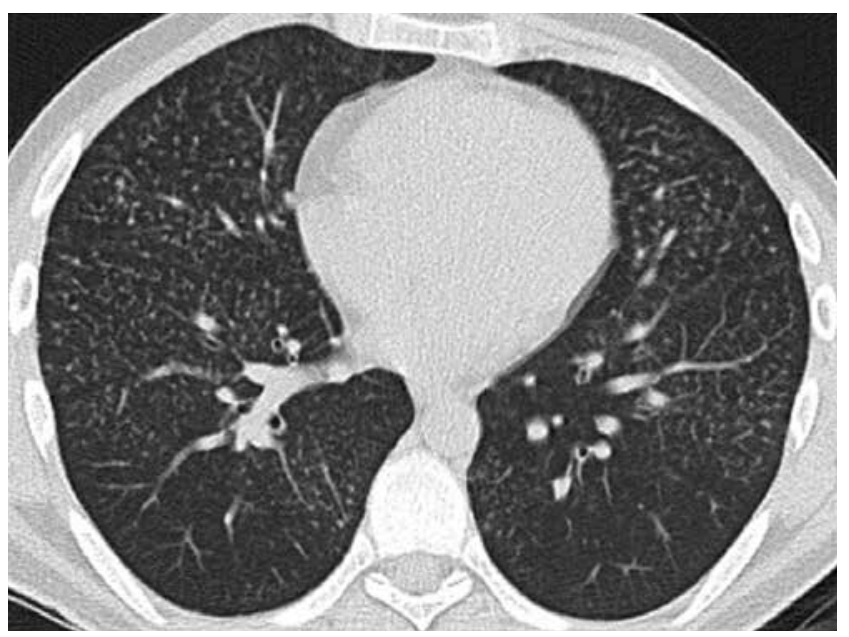

Figura 1. Neumonitis por hipersensibilidad (NH). Corte axial. Nódulos centrilobulillares, de contornos mal definidos, con densidad de vidrio esmerilado.

corresponder a dilatación arteriolar, colecciones de eosinófilos necróticos y macrófagos o pequeños focos de neumonía de organización. Otras alteraciones visibles en la tomografía computarizada de pacientes con granulomatosis eosinofílica con poliangeitis incluyen: áreas de vidrio esmerilado y consolidación, nódulos grandes y engrosamiento de septos interlobulillares (5) (figura 2).
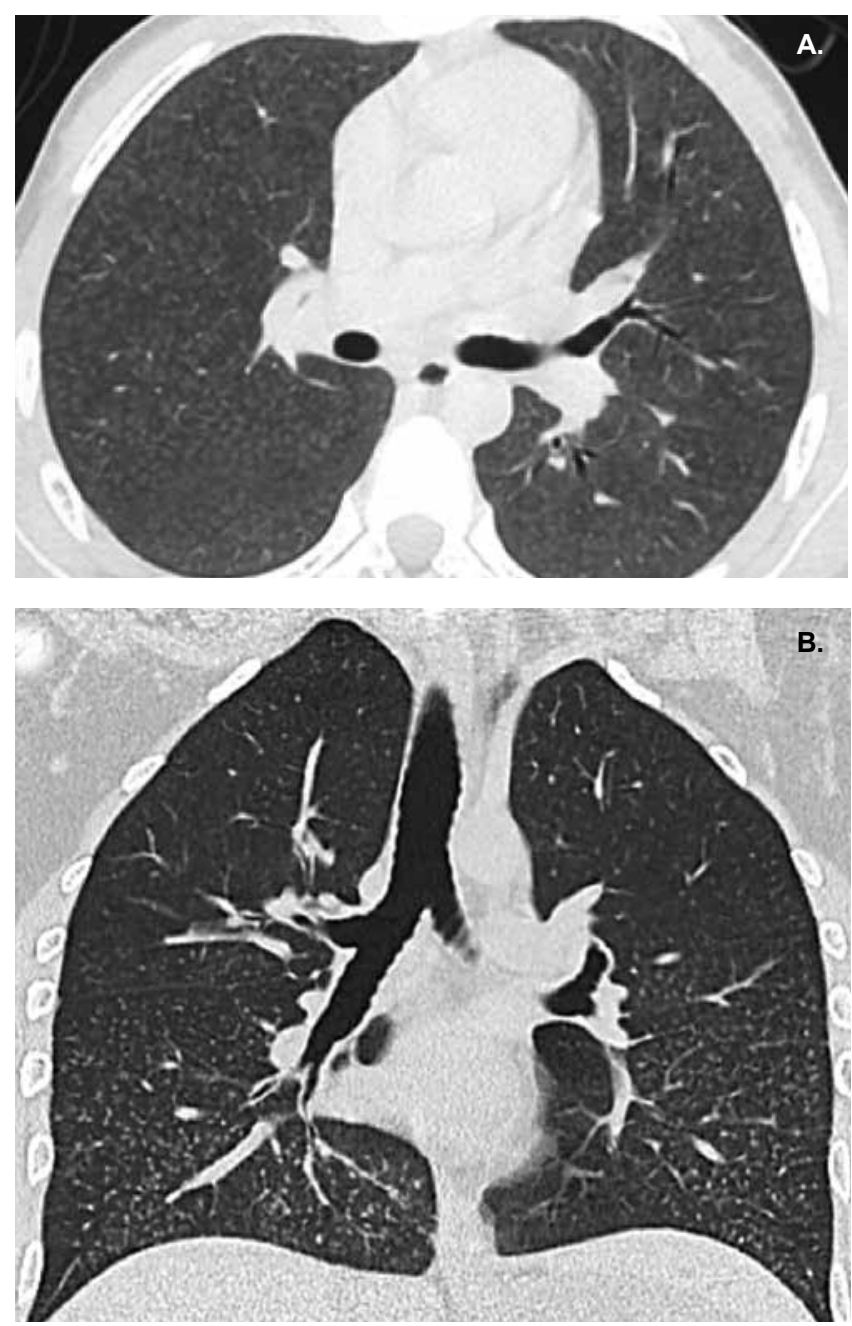

Figura 2. Poliangeitis eosinofílica. A y B: corte axial y reconstrucción coronal. Nódulos centrilobulillares con densidad de tejido blando, asociados con densidades lineales ramificadas centrilobulillares que conforman un patrón de "árbol en gemación".

\section{Bibliografía}

1. Webb WR, Müller NL, Naidich DP. High Resolution CT of the Lung. Fifth Edition. Lippincott Williams \& Wilkins. 2014;112$16 \mathrm{p}$.

2. Boitsios G, Bankier AA, Eisenberg RL. Diffuse pulmonary nodules. AJR Am J Roentgenol. 2010;194 (5):W354-66.

3. Lacasse Y, Girard M, Cormier Y. Recent advances in hypersensitivity pneumonitis. CHEST. 2012;142(1):208-17.

4. Silva CI, Churg A, Müller NL. Hypersensitivity pneumonitis: spectrum of high-resolution CT and pathologic findings. AJR. 2007; 188:334-44.

5. Silva CI, Müller NL, Fujimoto K, Johkoh T, Ajzen SA, Churg A. Churg-Strauss syndrome high resolution $\mathrm{CT}$ and pathologic findings. J Thorac Imaging. 2005;20(2):74-80. 